\title{
Uso de Geotecnologias no Estudo do Assoreamento do Açude de Vaca Brava - PB
}

\author{
Breno Tavares da Silva ${ }^{1}$; Guttemberg da Silva Silvino ${ }^{2}$; Aramis de Albuquerque Farias ${ }^{3}$
}

\begin{abstract}
Resumo: Atualmente, parece que os políticos e a população esqueceram o que é mata ciliar e sua importância, pois ao lado dos rios, reservatórios e lagos urbanos, em geral, não encontramos mais florestas conservadas. No meio rural o avanço da agricultura contribuiu para a redução da vegetação nas margens dos corpos d'água, criando um ambiente de insegurança hídrica. O reflexo dessas atividades, desenvolvidas nas bacias hidrográficas, é sentido diretamente nos rios e reservatórios. Com o solo descoberto ou com pouca vegetação, ocorre o transporte de sedimentos pela ação das chuvas, ocasionando o assoreamento e eutrofização dos corpos d'água. Este trabalho teve como principal objetivo mostrar os resultados obtidos no levantamento batimétrico automatizado do açude de Vaca Brava. A metodologia consistiu na utilização de técnicas de posicionamento por satélites (GPS) para a realização da batimetria, bem como de topografia convencional, além de recursos do sensoriamento remoto para a confecção de cartas digitais da microbacia. Os resultados da batimetria comparados com os dados do projeto inicial nos mostrou que houve uma diminuição no volume do reservatório de $\mathbf{1 0 , 5 0 \%}$, em 75 anos de funcionamento, correspondendo a uma taxa de $\mathbf{0 , 1 4 \%}$ ao ano (abaixo da média nacional que é de $0,5 \%$ ). Este baixo valor na taxa de assoreamento nos faz concluir o quanto é importante a conservação e preservação da mata ciliar no entorno e principalmente a montante dos reservatórios.
\end{abstract}

Palavras-Chave: Cobertura vegetal. Bacia hidrográfica. Geoprocessamento.

\section{Use of Geotechnologies in the Aggradation Study of the Vaca Brava Weir}

\begin{abstract}
Currently, it seems that politicians and people have forgotten what is riparian forest and its importance, as alongside rivers, reservoirs and urban lakes in general, we do not find conserved forests any more. In rural areas the advancement of agriculture has contributed to the reduction of the vegetation on the margins of water bodies, creating an environment of hydric insecurity. The result of these activities, developed in watersheds, is felt directly in rivers and reservoirs. Because of bare soil or low vegetation on the banks, sediment transport occurs through the action of rain, causing siltation and eutrophication of water bodies. This work aimed to show the results obtained in the automated bathymetric survey carried out in Vaca Brava weir. The methodology consisted in the use Global Satellite System (GPS) to perform the bathymetry, conventional topography methods and remote sensing data for making digital maps of the watershed. The bathymetry results compared to the reference data showed that, in 75 years of operation, there was a $10.50 \%$ decrease in the volume of the reservoir, corresponding to a rate of $0.14 \%$ per annum (below to $0.5 \%$ national average). This low rate of siltation leads us to conclude how important is conservation and preservation of riparian vegetation in the surroundings and especially upstream of the reservoirs.
\end{abstract}

Keywords: Vegetation cover. Watershed. Geoprocessing..

\footnotetext{
${ }^{1}$ Graduado em Engenharia Sanitária e Ambiental pela Universidade Estadual da Paraíba. Atualmente é Mestre em Manejo de Solo e Água, pela Universidade Federal da Paraíba, onde desenvolve trabalhos na parte de recursos hídricos. $1^{\circ}$ Tem. OTT. Adj Sec Tec - $3^{\circ}$ BEC. Contato: brenotavaresm@hotmail.com;

${ }^{2}$ Possui graduação em Engenharia Civil pela Universidade Federal da Paraíba, mestrado em Engenharia Agricola pela Universidade Federal da Paraíba e doutorado em RECURSOS NATURAIS pela UNIVERSIDADE FEDERAL DE CAMPINA GRANDE. Atualmente é Professor Adjunto da Universidade Federal da Paraíba - UFPB, lotado no Departamento de Solos e Engenharia Rural do Centro de Ciências Agrárias, Campus II - Areia-PB e Coordenador do Setor de Engenharia Rural do DSER.

${ }^{3}$ Engenheiro de Estruturas e Fortificação pelo Instituto Militar de Engenharia. Engenheiro Militar do Batalhão de Picos-PI. $1^{\circ}$ Tem. $3^{\circ}$ BEC. Contato: aramis.farias@gmail.com.
} 


\section{Introdução}

Historicamente o homem vem se utilizando dos recursos hídricos sem a preocupação de ver nestes um bem finito. A crescente demanda pelo uso dos recursos naturais foi acompanhada nas últimas décadas pela preocupação com a quantidade e a qualidade desse recurso.

De acordo com Sirigate (2005), como constituinte inorgânico encontrado em maior quantidade nos seres vivos ou como fator de consumo nas atividades humanas, a água é um elemento vital para os ecossistemas e básica para o desenvolvimento humano.

Em todo o mundo os múltiplos usos desse recurso abundante, porém finito, se dividem essencialmente em agricultura, indústria e consumo doméstico. Em termos gerais as fontes de água é muito mal distribuída e a poluição gerada pela atividade do homem está comprometendo as que se encontram ainda preservadas.

O aporte de efluentes domésticos, agropastoris e industriais lançados sem tratamento adequado em corpos hídricos e a erosão causada pela má conservação das matas ciliares, entre outros, são alguns exemplos dos responsáveis pela alteração das características físicas, químicas e biológicas dos rios e lagos, especialmente quando se tratam de mananciais de abastecimento público.

A remoção da vegetação nativa provoca vários danos ao meio ambiente, tais como: alteração climática, extinção de fauna e flora, promove e acentua o processo erosivo, causa prejuízos para a agricultura, etc. Quando à cobertura florestal se mantêm intacta a infiltração da água da chuva no solo é maior que em florestas com índice de desflorestamento acentuado.

O desmatamento altera as condições do solo e da vegetação em breve espaço de tempo, pois, provoca a lixiviação dos nutrientes do solo e, consequentemente altera seus atributos físicos e químicos. Além disso, ocasiona um rápido acúmulo de sedimentos nos lagos e nas planícies de inundação dos rios em virtude da erosão do solo nas vertentes (DREW, 1998).

Por tanto, é de suma importância a preservação da cobertura vegetal para evitar o transporte de sedimentos através da ação erosiva. Sobretudo as Áreas de Proteção 
Permanente ao redor dos corpos d'água, que são responsáveis por amenizar os efeitos do assoreamento.

As regras operacionais de açudes são baseadas nas curvas cota-área-volume que nem sempre estão atualizadas, uma vez que, os reservatórios perdem volume continuamente devido ao processo do assoreamento (CORRÊA FILHO, 2005).

Uma das metodologias para determinar o assoreamento de açudes é o levantamento batimétrico automatizado. Este levantamento pode ser definido como sendo o conjunto dos princípios, métodos e convenções utilizados para determinar a medida do contorno, da dimensão e da posição relativa da superfície submersa dos mares, rios, lagos, canais.

O presente trabalho objetivou o levantamento batimétrico do açude Vaca Brava, no município de Areia - PB, de forma a gerar dados que sirvam de apoio à gestão deste manancial por parte do Governo do Estado da Paraíba, principalmente à Agência Executiva de Gestão das Águas da Paraíba - AESA, para auxiliar nas tomadas de decisões e facilitar o gerenciamento e utilização racional deste reservatório.

\section{Metodologia}

A área de estudo localiza-se na mesorregião do Agreste Paraibano e na microrregião do brejo Paraibano. O trabalho foi desenvolvido na bacia hidrográfica do açude Vaca Brava, localizada entre os municípios de Areia e Remígio no Estado da Paraíba (Figura 1). A bacia está inserida nas seguintes coordenadas geográficas: $06^{\circ} 57^{\prime} 48^{\prime \prime}$ e $06^{\circ} 59^{\prime} 43^{\prime \prime}$ de latitude Sul e os meridianos $35^{\circ} 44^{\prime} 03$ ” e $35^{\circ} 45^{\prime} 59^{\prime \prime}$ de longitude Oeste, com uma área de aproximadamente 1403 ha. Parte dessa área constitui reserva de Mata Atlântica de Altitude a qual preserva a área de captação do reservatório de Vaca Brava, que abastece três municípios do agreste paraibano, compreendendo uma população de aproximadamente 92.000 pessoas.

O Relevo caracteriza-se como ondulado (com declives 8 a 20\%) a fortemente ondulados (de 20 a 45\%) (BRASIL, 1972).

O clima predominante na região, de acordo com a classificação de Köppen, é "As" quente e úmido com chuvas de outono e inverno (PARAÍBA, 1985). A precipitação anual 
Id on Line Revista Multidisciplinar e de Psicoloqia

Id on Line Multidisciplinary and Psycology Journal

varia de 800 a $1600 \mathrm{~mm}$, com chuvas concentradas nos meses de junho a agosto e temperaturas que variam de $18^{\circ} \mathrm{C}$ a $26^{\circ} \mathrm{C}$.

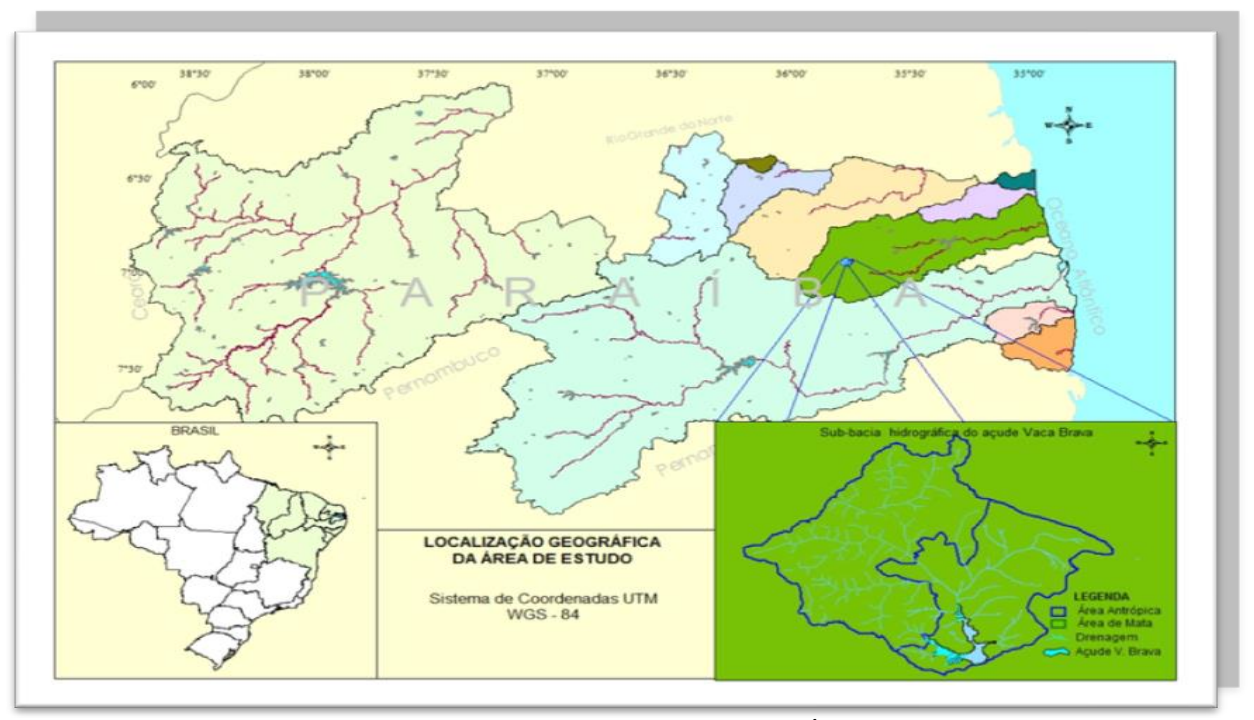

Figura 1 - Localização Geográfica da Área de Estudo

\section{Material}

\section{Levantamento Da Área Molhada}

Neste estudo foi efetuado um levantamento batimétrico automatizado da área molhada da bacia hidráulica com utilização de:

- Um par de GPS modelo Trimble R4 - RTK (L1/L2);

- Barco de alumínio, com capacidade para 4 pessoas e todo equipamento necessário;

- Ecobatímetro de feixe único, modelo OHMEX e um transdutor;

- Software para planejamento e execução dos dados do levantamento GPS (Autocad Vs. 2000 e GPS Trackmaker vs. 13,8);

- Software pós-processamento dos dados do levantamento GPS (TBC vs 2.7.0); Software para processamento dos dados de profundidade (SonarLite vs. 2000); 
- Software para geração do Modelo Digital do Terreno a partir dos dados batimétricos (SURFER vs. 9.0);

- Software para eliminação de profundidades incorretas (MapInfo vs. 11.0).

\section{Levantamento da Área Seca}

- Estação Total, modelo FOIF;

- $\quad$ Software TopoEVN 5.3

\section{Métodos}

\section{Batimetria Automatizada}

O levantamento batimétrico automatizado foi realizado no dia 26 de Julho de 2016 onde os dados de posição e profundidade foram pré-processados e organizados em dois arquivos de pontos no formato do Microsoft Excel TM no formato (.xls): O primeiro arquivo contendo os dados contorno posição bidimensional (x e y) e o segundo composto pelas informações internas de posição e profundidade, tridimensional (x, y e z).

A referência do nível da água adotada foi a cota 507,88 m e ao arquivo dos pontos internos foram adicionados os dados do contorno do açude atribuindo o valor 0 (zero) ao campo profundidade (coordenada $\mathrm{z}$ ), estando desta forma, o arquivo pronto para $\mathrm{o}$ processamento.

$\mathrm{O}$ arquivo contendo os pontos tridimensionais foi processado no software Surfer vs. 9.0 e interpolados gerando uma malha tridimensional. No processo de interpolação, foi utilizado o método do Inverso do Quadrado da Distância, que é um método que leva em consideração as características espaciais das variáveis regionalizadas e apresenta fidelidade aos dados originais, boa suavidade das curvas interpoladas e boa precisão geral. 


\section{Levantamento Topográfico Da Área Seca}

Para o cálculo total do volume do reservatório foi preciso fazer um levantamento topográfico convencional para complementar o levantamento batimétrico. Este levantamento foi realizado do dia 27 de julho a 5 de agosto de 2016.

A referência adotada para esta etapa foi a partir da cota 507,88 m, correspondente ao nível da água. A coleta dos dados possibilitou a geração de um arquivo com posição e cotas (x, y e z) até a cota $511,00 \mathrm{~m}$.

$\mathrm{O}$ arquivo contendo os pontos tridimensionais foi processado no software TopoEVN 5.3 e interpolados gerando uma malha tridimensional. No processo de interpolação também foi utilizado o método Inverso do Quadrado da Distância e gerada a malha tridimensional e o modelo digital do terreno. As curvas de nível foram confeccionadas na equidistância de 1,00 m para a obtenção das tabelas cota x área e cota x volume.

\section{Resultados e Discussão}

A tabela cota $\mathrm{x}$ área $\mathrm{x}$ volume atual foi gerada com equidistâncias de um metro, obedecendo às mesmas condições da confecção tabela original elaborada pelo DNOCS. Observa-se pelos dados comparativos do projeto inicial de 1937 com os dados obtidos em 2012 (Tabela 1), que o volume máximo de projeto, cuja cota é 511,30 m corresponde a 3.699.613,00 $\mathrm{m}^{3}$, e atualmente foi obtido na mesma cota um volume de $3.311 .229,47 \mathbf{m}^{3}$, representando um índice de assoreamento de $\mathbf{1 0 , 5 0 \%}$ em relação à capacidade de acumulação máxima do projeto inicial. Esta taxa corresponde a uma media anual de assoreamento de $\mathbf{0 , 1 4 \%}$, valor muito inferior à média nacional que é de $\mathbf{0 , 5 0 \%}$ ao ano e inferior a média mundial de 1,00\% (MAHMOOD, 1987 apud CARVALHO et al, 2000). 
Id on Line Revista Multidisciplinar e de Psicologia

Id on Line Multidisciplinary and Psycology Journal

Tabela 1. Dados de Cota x Área x Volume do açude Vaca Brava nos anos 1937 e 2016.

\begin{tabular}{|c|c|c|c|c|c|}
\hline \multicolumn{3}{|c|}{ DADOS DNOCS - 1937} & \multicolumn{3}{|c|}{ DADOS ATUAIS - 2016} \\
\hline Cota $(m)$ & Área $\left(m^{2}\right)$ & \begin{tabular}{|c|}
$\begin{array}{c}\text { Volume } \\
\left(\mathrm{m}^{3}\right)\end{array}$ \\
\end{tabular} & $\begin{array}{l}\text { Cota } \\
\text { (m) }\end{array}$ & Área $\left(\mathbf{m}^{2}\right)$ & Volume $\left(\mathbf{m}^{3}\right)$ \\
\hline 490,00 & $21.250,00$ & $10.625,00$ & 490,00 & $2.857,65$ & $2.977,89$ \\
\hline 491,00 & $32.500,00$ & $60.000,00$ & 491,00 & $20.180,66$ & $13.530,66$ \\
\hline 492,00 & $43.750,00$ & $109.375,00$ & 492,00 & $27.352,90$ & $37.187,79$ \\
\hline 493,00 & $55.000,00$ & $158.750,00$ & 493,00 & $36.011,62$ & $69.053,31$ \\
\hline 494,00 & $66.250,00$ & $208.125,00$ & 494,00 & $43.873,93$ & $108.972,19$ \\
\hline 495,00 & $77.500,00$ & $257.500,00$ & 495,00 & $54.440,22$ & $157.806,71$ \\
\hline 496,00 & $90.500,00$ & $367.500,00$ & 496,00 & $68.190,99$ & $219.136,02$ \\
\hline 497,00 & $103.500,00$ & $477.500,00$ & 497,00 & $84.281,36$ & $294.934,03$ \\
\hline 498,00 & $116.500,00$ & $587.500,00$ & 498,00 & $98.814,83$ & $386.670,74$ \\
\hline 499,00 & $129.500,00$ & $697.500,00$ & 499,00 & $114.370,43$ & $493.439,63$ \\
\hline 500,00 & $142.500,00$ & $807.500,00$ & 500,00 & $130.746,76$ & $616.962,02$ \\
\hline 501,00 & $162.500,00$ & $1.000 .000,00$ & 501,00 & $147.338,38$ & $758.469,87$ \\
\hline 502,00 & $182.500,00$ & $1.192 .500,00$ & 502,00 & $162.568,83$ & $916.882,98$ \\
\hline 503,00 & $202.500,00$ & $1.385 .000,00$ & 503,00 & $180.698,11$ & $1.093 .375,27$ \\
\hline 504,00 & $222.500,00$ & $1.577 .500,00$ & 504,00 & $203.003,80$ & $1.293 .232,59$ \\
\hline 505,00 & $242.500,00$ & $1.770 .000,00$ & 505,00 & $226.006,70$ & $1.520 .057,58$ \\
\hline 506,00 & $263.500,00$ & $1.962 .500,00$ & 506,00 & $244.533,93$ & $1.776 .511,69$ \\
\hline 507,00 & $284.500,00$ & $2.155 .000,00$ & 507,00 & $261.576,72$ & $2.054 .216,41$ \\
\hline 508,00 & $305.500,00$ & $2.347 .500,00$ & 508,00 & $294.437,12$ & $2.263 .435,00$ \\
\hline 509,00 & $326.500,00$ & $2.540 .000,00$ & 509,00 & $315.503,74$ & $2.518 .406,00$ \\
\hline 510,00 & $347.500,00$ & $3.245 .000,00$ & 510,00 & $337.194,12$ & $2.894 .755,00$ \\
\hline 510,50 & 361.250,00 & $3.453 .125,00$ & 510,50 & $349.280,00$ & $3.069 .395,00$ \\
\hline 511,00 & $375.000,00$ & $3.661 .250,00$ & 511,00 & $361.365,53$ & $3.244 .035,00$ \\
\hline 511,30 & 383.250,00 & $3.699 .613,00$ & 511,30 & $371.054,73$ & 3.311.229,47 \\
\hline 512,00 & $402.500,00$ & $3.789 .125,00$ & 512,00 & $389.597,31$ & $3.549 .563,38$ \\
\hline 513,00 & $430.000,00$ & $4.405 .019,00$ & 513,00 & $416.812,67$ & $3.904 .543,24$ \\
\hline 514,00 & $457.500,00$ & $4.843 .452,00$ & 514,00 & $444.882,07$ & $4.276 .585,30$ \\
\hline 515,00 & $485.000,00$ & $5.326 .250,00$ & 515,00 & $473.805,52$ & $4.665 .689,54$ \\
\hline
\end{tabular}

A vegetação da microbacia do açude Vaca Brava é um remanescente de Mata Atlântica. Possui uma formação densa, de árvores altas (às vezes superiores a 30m) e troncos com 
Id on Line Revista Multidisciplinar e de Psicoloqia

Id on Line Multidisciplinary and Psycology Journal

diâmetros consideráveis, com inúmeras espécies de Palmeiras, Ipês, Pau-Ferro, etc. O verde característico toma conta da paisagem o ano inteiro, independentemente de estações chuvosas.

Para os recursos hídricos, a conservação da cobertura vegetal, sobretudo a florestal, é essencial para sua conservação. A retirada da vegetação nativa provoca vários danos ao meio, por exemplo: alteração climática, extinção da fauna e da flora, além de acentuar os processos erosivos, levando ao assoreamento de reservatórios.

A Figura 2 mostra a Composição Multiespectral Ajustada (CMA), que nos permite analisar o comportamento da cobertura vegetal da área de estudo. $\mathrm{Na}$ imagem observa-se na cor verde as áreas com cobertura vegetal, enquanto que as cores "magenta" e, por vezes “ciano", representam áreas de solo com cobertura vegetal rala a solo exposto.

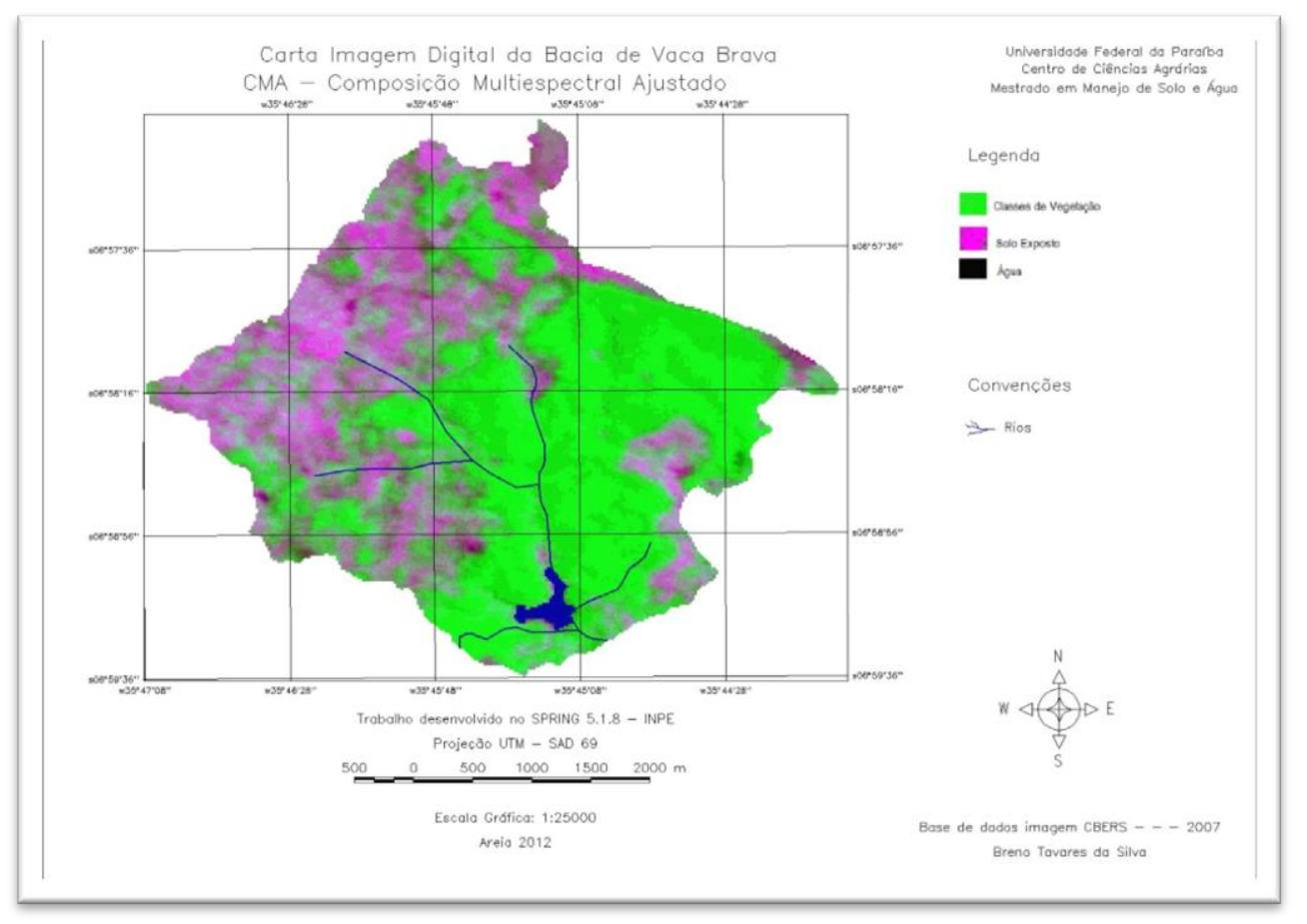

Figura 2. Composição Multiespectral Ajustada (CMA) 
A composição mostra que a micro-bacia do açude Vaca Brava tem uma área ainda bastante preservada, principalmente ao redor do reservatório.

Isto se deve por força de lei, pois a Reserva Ecológica Mata do Pau Ferro é uma gleba de terra de 600 ha, localizada dentro da micro bacia de Vaca Brava, pertencente ao Governo do Estado da Paraíba, criado pelo Decreto Lei no 14.832, de 19 de Outubro de 1992 e localizase na microrregião do Brejo Paraibano. Isto explica o porquê da taxa de assoreamento ter dado abaixo da média nacional e mundial, que são de $0,5 \%$ ao ano e 1,00\% ao ano, respectivamente.

A Figura 3, mostra a mata ciliar do açude de Vaca Brava, evidenciando uma mata bem preservada evitando os efeitos dos processos erosivos neste reservatório.

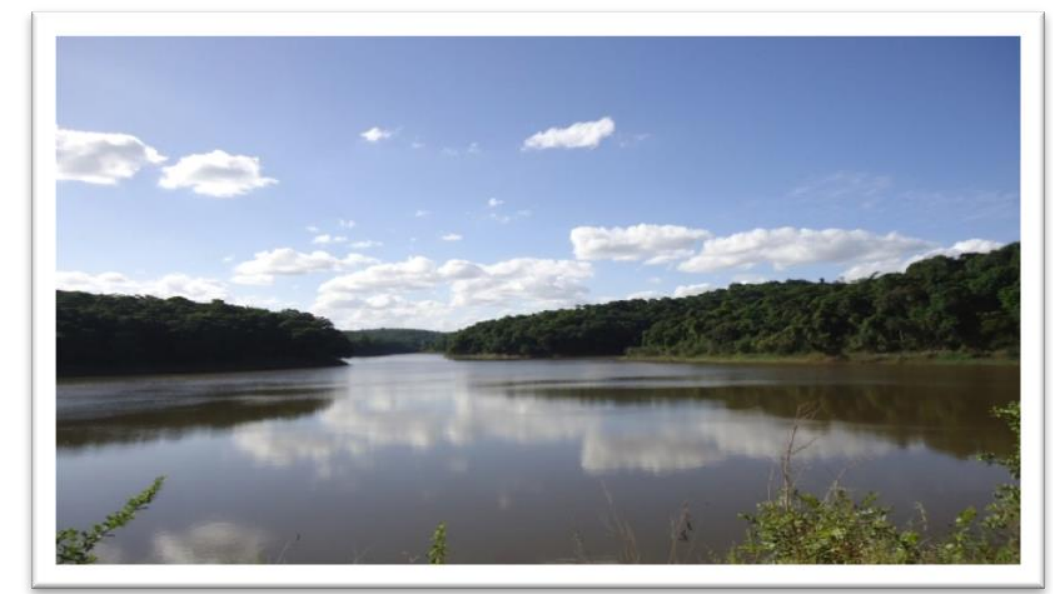

Figura 3. Mata ciliar do reservatório de Vaca Brava

O estudo de campo permitiu visualizar que em toda extensão das margens do reservatório predomina uma vegetação densa, o que justifica a baixa taxa de assoreamento encontrada no reservatório, pois as árvores impedem que a água da chuva, através do escoamento superficial, leve para dentro do reservatório o sedimento que poderia desprender do solo caso não existisse vegetação.

Apesar de que a região ainda encontra-se relativamente preservada, alguns problemas ambientais são diagnosticados, pois é possível encontrar diversas clareiras no meio da mata, evidenciando um desrespeito por parte da comunidade daquela área, e um descaso do Poder Público que não fiscaliza a Reserva. 


\section{Conclusões}

O índice de assoreamento do reservatório de Vaca Brava foi de $\mathbf{1 0 , 5 0 \%}$, o que corresponde a uma taxa de aproximadamente $\mathbf{0 , 1 4 \%}$ ao ano, valor este bem abaixo da média nacional e mundial, que é de $\mathbf{0 , 5}$ e $\mathbf{1 , 0 \%}$ ao ano, respectivamente.

Fica comprovada a importância da vegetação ciliar para o controle da erosão e consequentemente para a preservação dos reservatórios d'água.

A bacia hidrográfica ainda possui uma área relativamente grande de vegetação nativa preservada.

O uso de geotecnologias se mostrou bastante eficiente no cálculo do índice de assoreamento deste reservatório, bem como na geração de mapas de cobertura vegetal

\section{Agradecimentos}

Ao CNPq pelo apoio financeiro, ao Programa de Pós Graduação em Manejo de Solo e Água/UFPB pelo apoio científico, e a Agência Executiva de Gestão das Águas da Paraíba AESA pelo suporte técnico e logístico.

\section{Referências}

BRASIL. Ministério da Agricultura. Escritório de Pesquisa e Experimentação. Equipe de Pedologia e Fertilidade do Solo. Estado da Paraíba. I. Interpretação para uso agrícola dos solos do Estado da Paraíba. Rio de Janeiro, 1972 (Boletim Técnico, 15; SUDENE. Série Pedologia, - ).

CARVALHO, N. O.; JÚNIOR, N. P. F.; SANTOS, P. M. C. e LIMA, J. E. F. W., Guia de Avaliação de Assoreamento de Reservatórios, Brasília, DF, ANEEL - 2000. 
Id on Line Revista Multidisciplinar e de Psicoloqia

Id on Line Multidisciplinary and Psycology Journal

CORRÊA FILHO, C.R.R.; ALBERTIN, L.L.; MAUAD, F.F. Determinação dos polinômios cota $x$ área $x$ volume utilizando a sonda acoustic doppler profiler (adp) no reservatório de barra bonita - SP. Revista Minerva: Pesquisa e Tecnologia. v. 2, n. 1, jan/jun 2005.

DREW, David. Processos interativos homem-meio ambiente. $4^{\mathrm{a}}$ ed. Rio de Janeiro: Bertrand Brasil, 1998, pp 92-94, 158;

PARAÍBA. Secretaria da Educação. Universidade Federal da Paraíba. Atlas Geográfico daParaíba. João Pessoa: GRAFSET, 1985.

SIRIGATE, Priscila. Gestão da qualidade ambiental da água de mananciais de abastecimento público como estratégia de redução de custos. In: ENCONTRO NAC. DE ENG. DE

PRODUÇÃO, 25., 2005, Porto Alegre. ENEGEP 2005. Porto Alegre: Abepro, 2005. p. 5288 - 5294. Disponível em: <http://pg.utfpr.edu.br/dirppg/ppgep/ebook/2005/E-

book\%202006_artigo\%207.pdf>. Acesso em: 22 set. 2011.

Como citar este artigo (Formato ABNT):

SILVA, Breno T. da; SILVINO, . Uso de Geotecnologias no Estudo do Guttemberg da S.; FARIAS, Aramis A. Assoreamento do Açude de Vaca Brava - PB. Id on Line Revista Multidisciplinar e de Psicologia, 2017, vol.11, n.37, p. 513-523. ISSN: 1981-1179.

Recebido: 11.09.2017

Aceito: 13.09.2017 